\title{
Isolation and characterization of the transient, luciferase-bound flavin-4a-hydroxide in the bacterial luciferase reaction
}

\author{
Manfred Kurfuerst ${ }^{a}$, Peter Macheroux ${ }^{b}$, Sandro Ghisla ${ }^{b}$ \\ and J. Woodland Hastings ${ }^{a}$ \\ ${ }^{a}$ Department of Cellular and Developmental Biology, Harvard University, Cambridge, MA (U.S.A.) \\ and ${ }^{b}$ Department of Biology, University of Konstanz, Konstanz (F.R.G.)
}

Key words: Bioluminescence; Oxygen activation; Flavin intermediate; Luciferase; (Bacteria)

Procedures and conditions have been established such that the unstable enzyme-bound flavin intermediate produced in the bacterial luciferase reaction can be isolated as approximately $70 \%$ of the flavin product, the remaining being the final product, FMN. The structure of the intermediate is proposed to be that of a luciferase-bound 4a,5-dihydroflavin-4a-hydroxide. The intermediate has a half-life of $33 \mathrm{~min}$ at $2^{\circ} \mathrm{C}$ and decays spontaneously to give $\mathrm{H}_{2} \mathrm{O}$ and luciferase-bound FMN with an activation enthalpy of about 120 $\mathrm{kJ} / \mathrm{mol}$. It has an absorption spectrum $\left(\lambda_{\max }=360 \mathrm{~nm}\right)$ that is consistent with the proposed structure, and a fluorescence emission $\left(\lambda_{\max }=\mathbf{4 8 5} \mathrm{nm}\right)$ that matches the bioluminescence emission closely.

\section{Introduction}

The luciferase in bioluminescent bacteria is a flavinmonooxygenase which, in the course of activating molecular oxygen and oxidizing a longchain aldehyde, emits light $\left(\lambda_{\max }=490 \mathrm{~nm}\right)$ [1]. Although flavoprotein monooxygenases include a variety of specificities, the emission of light makes luciferase unique. The identity of the excited species and of the emitting chromophore(s) is of key importance for the understanding of the bioluminescent process. In the pure system the structure of the intermediate luciferase-bound flavin4a-hydroperoxide has been specified [2,3]. Although its fluorescence closely matches the bioluminescence spectrally [4], the peroxide cannot be the emitter, since it occurs prior to the reaction with aldehyde, the step which provides the energy

Correspondence: S. Ghisla, Universität Konstanz, Postfach 5560, D-7750 Konstanz, F.R.G. required. In a previous communication we have reported the occurrence of a further intermediate having a similar fluoresence, which occurs subsequent to light emission in spent reaction mixtures [5]. Its chromophore was proposed to be the luciferase bound flavin-4a-hydroxide, and its excited state was postulated to be the flavin emitter in the bacterial bioluminescent reaction, at least in those cases in which no further specific emitter proteins $[6,7]$ are present. In the present study we have extended the earlier work by establishing conditions such that subsequent to light emission this fluorescent chromophore could be isolated as the principal flavin component. Its spectral and kinetic properties are described and compared to those of other flavin intermediates in the bacterial bioluminescent reaction.

\section{Materials and Methods}

Luciferase was isolated from the luminous bacterium Vibrio harveyi, mutant strain M-17 [8] 
and purified by the method of hastings et al. [9]. The enzyme concentration was determined by absorption measurements using an $E_{280}$ value of $74 \mathrm{mM}^{-1} \cdot \mathrm{cm}^{-1}$ [10]. The purity of the luciferase used was greater than $95 \%$, as determined by slab sodium dodeclsuflate polyacrylamide gel electrophoresis [11].

FMN was obtained from Sigma and decanal from Aldrich. The equilibration buffer was prepared by mixing $100 \mu \mathrm{l}$ of decanal solution $(10 \mu \mathrm{l}$ decanal in $90 \mu 1$ ethanol) with $100 \mathrm{ml}$ of $0.1 \mathrm{M}$ phosphate buffer at the indicated $\mathrm{pH}$, sonicating for $2 \mathrm{~min}$, cooling to $5^{\circ} \mathrm{C}$ and filtering just prior to use. All other reagents were of analytical grade. Absorption spectra were measured with an UVIKON 820 (Kontron) spectrophotometer. Fluorescence spectra were recorded with a PerkinElmer MFP-44 spectrofluorimeter, and are presented without applying corrections for lamp profile, phototube sensitivity or monochromator efficiency. Such corrections would shift the peaks to the blue by several $\mathrm{nm}$.

The putative luciferase-bound flavin-4a-hydroxide was prepared by running the reaction on a molecular sieve column at $5^{\circ} \mathrm{C}$ and collecting the protein fraction of the spent reaction mixtures in the eluate just after the void volume, as follows: a mixture containing $100 \mu \mathrm{l}$ luciferase $\left(4.6 \cdot 10^{-4}\right.$ M), $25 \mu \mathrm{I}$ FMN $\left(4.5 \cdot 10^{-3} \mathrm{~m}\right)$ and $175 \mu \mathrm{l}$ equilibration buffer was chemically reduced with a minimal amount of solid sodium dithionite and promptly applied to a Sephadex G-25 column (void volume $5 \mathrm{ml}$ ), equilibrated with the aldehyde (decanal)-containing buffer. After about $10 \mathrm{~s}$ of elution, a bright band of bioluminescence could be observed in the upper part of the column, indicating the reaction of the flavin-4a-hydroperoxide with decanal. Bioluminescence disappeared well prior to the elution $(15 \mathrm{~min})$ of the protein fraction $(0.5 \mathrm{ml})$, which was collected and transferred to a cuvette for measurements of fluorescence and/or absorbance spectra. From these fractions we could detect neither residual luciferase bound flavin hydroperoxide activity (by injecting aliquots of the fractions into a freshly prepared decanal solution) nor the formation of $\mathrm{H}_{2} \mathrm{O}_{2}$. The measurement of $\mathrm{H}_{2} \mathrm{O}_{2}$ was performed using peroxidase (Merck) and 2,2'-azinodi(3-ethyl)benzthiazolin sulfonic acid (ABTS, Boehringer) as electron donor as described by others [12]. Amounts of $\mathrm{H}_{2} \mathrm{O}_{2}$ in the range of $0.5-1 \mathrm{nmol}$ could be satisfactorily detected using the corresponding amounts of luciferase-bound flavin-4a-hydroperoxide prepared as described earlier [2] or commercial $\mathrm{H}_{2} \mathrm{O}_{2}$. The determination of 1-10 nmol of authentic $\mathrm{H}_{2} \mathrm{O}_{2}$ was not impaired by the presence of $75 \mu \mathrm{M}$ luciferase; the sensitivity of the method would have allowed us to detect $5 \cdot 10^{-7} \mathrm{M} \mathrm{H}_{2} \mathrm{O}_{2}$ in $1 \mathrm{ml}$ samples, i.e., about $5 \%$ of the $\mathrm{H}_{2} \mathrm{O}_{2}$ which would have formed if all of the intermediate was flavin4a-hydroperoxide. The flavin content of a typical preparation of intermediate was $10 \mu \mathrm{M}$.

\section{Results}

\section{Formation and fluorescence of the intermediate}

In previous attempts to obtain the intermediate only $10-20 \%$ of the total flavin consisted of the desired flavin-4a-hydroxide chromophore, the major component being oxidized FMN (partially) bound to luciferase [5]. In this study we succeeded in substantially increasing the yield of flavin-4ahydroxide by carrying out the reaction on a Sephadex $\mathrm{G}-25$ column at $0-4^{\circ} \mathrm{C}$ in the presence of excess long-chain aldehyde, at $\mathrm{pH} 8.5$, and in 0.1 $M$ phosphate buffer. These conditions resulted in a favourable compromise between rates of formation and of decay of the flavin-4a-hydroxide. As compared to $\mathrm{pH} 7$ the rate of decay of the flavin4 a-hydroxide is reduced by about 3.5 -fold, while the rate of light emission decay, corresponding to formation of the 4a-hydroxide, is lowered only about 2-fold. The flow of the column was adjusted so as to ensure that no flavin-4a-hydroperoxide was present in the eluate: light emission had ceased at the point in time when the protein was collected.

As shown in Fig. 1, this procedure results in preparations containing predominantly flavin-4ahydroxide as the chromophore. The amount of oxidized FMN present in this preparation is about $30 \%$, as estimated from its absorption spectrum (Fig. 2). When the fluorescence emission spectrum (trace 1) is corrected for this amount of FMN emission (based on the fluroescence of trace 6), the spectrum of trace (a) (Fig. 1) results, which has a maximum at about $485 \mathrm{~nm}$.

The conversion of the intermediate to oxidized 


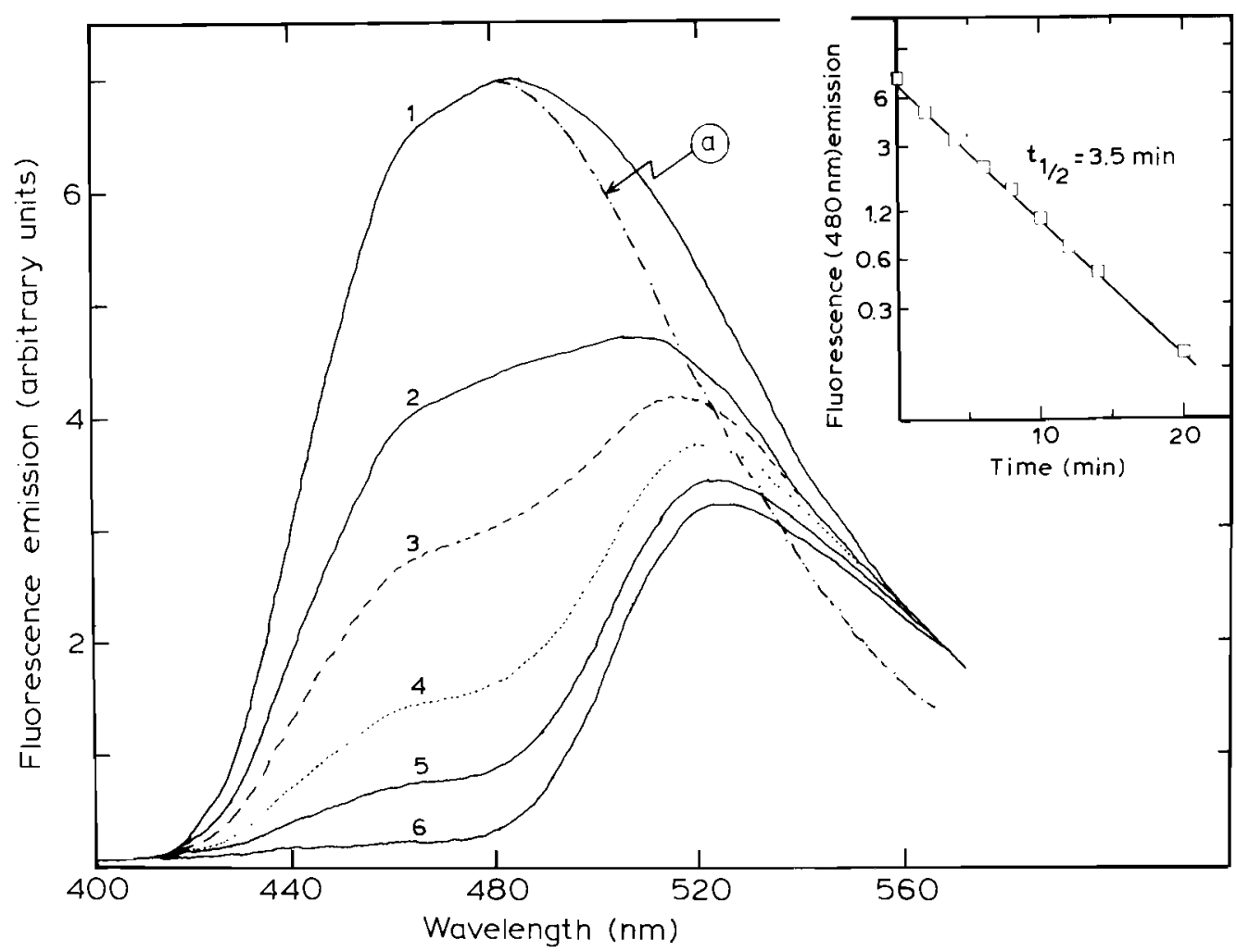

Fig. 1. Fluorescence emission spectrum of the luciferase-bound flavin intermediate immediately subsequent to the light-emitting reaction at $\mathrm{pH} 8.5$ and its decay with time at $12^{\circ} \mathrm{C}$ to oxidized flavin. With excitation at $380 \mathrm{~nm}$, the fluorescence emission spectrum of the preparation was recorded within $1 \mathrm{~min}$ after its elution from the aldehyde-equilibrated Sephadex column (trace 1). The next four traces were recorded after 2, 4, 8 and $12 \mathrm{~min}$. Trace 6 shows the final spectrum taken at $12^{\circ} \mathrm{C}$ after having warmed the sample to $25^{\circ} \mathrm{C}$. Trace (a) was obtained by subtracting the fluorescence emission of FMN (about $30 \%$ of trace 6) from trace 1 . The inset shows the kinetics of the decrease in fluorescence emission at $480 \mathrm{~nm}\left(t_{1 / 2}=210 \mathrm{~s} ; k=3.3 \cdot 10^{-3} \mathrm{~s}^{-1}\right)$.

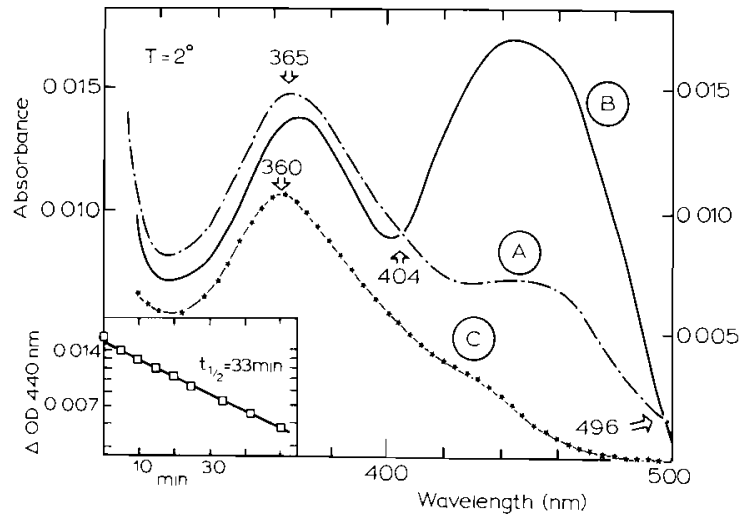

Fig. 2. Absorption spectra of the protein fraction of a spent reaction mixture before $(A)$ and after $(B)$ decay at $2{ }^{\circ} \mathrm{C}$ and $\mathrm{pH}$ 8.5 , and $(C)$ the calculated absorption spectrum of the intermediate, the luciferase-bound flavin-4a-hydroxide. Immediately after elution of the protein fraction from an aldehyde-equilibrated Sephadex column, its fluoreseence spectrum was mea-
FMN is accompanied by a decrease in fluorescence emission at $480 \mathrm{~nm}$, which is pseudo-firstorder over nearly two orders of magnitue (Fig. 1, inset). The fluorescence of the FMN in trace 1 cannot be resolved, partly due to the fact that the envelope of the fluorescence from the flavin-4ahydroxide obscures it, and partly because the fluorescence of luciferase-bound FMN is highly quenched [10]. The fluorescence of the flavin-4a-

sured (trace not shown). An absorption spectrum was then recorded (trace $\mathrm{A}$ ) and the absorbance changes at $2^{\circ} \mathrm{C}$ were monitored with time at $440 \mathrm{~nm}$ (corresponding to a peak of oxidized flavin); the kinetics of this decay are shown in the inset. The final absorption spectrum (after $3 \mathrm{~h}$ ) is given in trace B. The absorption spectrum of the flavin itnermediate (luciferase flavin-4a-hydroxide) was calculated by subtraction of $30 \%$ of trace B from trace A. 
hydroxide is characterized by a shoulder on the blue side, which is also present in the fluorescence of the flavin-4a-hydroperoxide [4].

\section{Absorbance properties of the intermediate}

The absorption spectrum of a similar preparation of flavin-4a-hydroxide is shown in Fig. 2. Trace $\mathrm{A}$ was acquired about $18 \mathrm{~min}$ after beginning the experiment, about $1 \mathrm{~min}$ after elution from the G-25 column. In the conversion of this species to luciferase-bound oxidized FMN the absorbance changes occur essentially isosbestically; trace $B$ was acquired after conversion was complete. The corrected spectrum of the intermediate (trace C) was determined by subtracting $30 \%$ of trace $B$ from trace $A$. The decay is pseudo-firstorder and monophasic (Fig. 2, inset). The amount of FMN observed in trace A corresponds reasonably well with the amount expected from the reaction during the period of elution, based on a $t_{1 / 2}$ for the decay of about $33 \mathrm{~min}$ and assuming that most of the flavin-4a-hydroxide is formed in the first few minutes after application to the colum. This also indicates that most of the flavin-4a-hydroperoxide being formed is converted to luciferase-bound flavin-4a-hydroxide, and that side-reactions do not play a major role. The absorption spectrum of the flavin-4a-hydroxide is shifted hypsochromically by about $10 \mathrm{~nm}$ as compared to that of the flavin-4a-hydroperoxide [13]. This compares very well with a blue shift of $5-10 \mathrm{~nm}$ observed by Entsch et al. [14] for the corresponding species bound to $p$-hydroxybenzoate hydroxylase and also for phenol hydroxylase [15]. The absorption spectrum is also characterized by a shoulder at about $430 \mathrm{~nm}$ which is also present in that of the flavin-4a-hydroperoxide [2]. The fluorescence excitation (not shown) and emission spectra (Fig. 1) match respectively the absorption spectrum (Fig. 2) and the bioluminescence emission spectrum satisfactorily.

\section{Structure and stability of the intermediate}

The observations reported here are consistent with a minimal scheme in which the flavin-4a-hydroxide decays in an irreversible, rate-limiting step to form $\mathrm{H}_{2} \mathrm{O}$ and luciferase-bound FMN (LFMN).

$\mathrm{L}-\mathrm{FMNH}-4 \mathrm{a}-\mathrm{OH} \rightarrow \mathrm{L}-\mathrm{FMN}+\mathrm{H}_{2} \mathrm{O} \rightleftarrows \mathrm{L}+\mathrm{FMN}$
This step is dependent on $\mathrm{pH}$, and slowest at $\mathrm{pH}>8.5$. In $100 \mathrm{mM}$ phosphate buffer the $\mathrm{pH}$ dependence of the rate of decay reflects an apparent $\mathrm{p} K$ of about 7, as shown in Fig. 3. This dependence is likely to reflect (also) the concentration ratio of $\mathrm{HPO}_{4}^{2-} / \mathrm{H}_{2} \mathrm{PO}_{4}^{-}$, since the stability of luciferase intermediates is known to be dependent on the nature and concentration of the electrolyte [18]. However, keeping the concentration of $\mathrm{NaCl}$ high and constant at $400 \mathrm{mM}$, a comparable $\mathrm{pH}$ dependence was observed (Fig. 3), indicating that the stability of the intermediate is influenced by several interdependent factors. For the purpose of preparation of the intermediate, Fig. 3 shows clearly that the best conditions are found at $\mathrm{pH} \approx 8.5$. The bound FMN resulting from the decay of the intermediate is in equilibrium with free FMN and luciferase, consistent with the strong quenching of the FMN fluorescence due to binding to the enzyme [10].

As with the luciferase-bound flavin-4a-hydroperoxide [2] and the FMN semiquinone [16], the rate of decay of the flavin-4a-hydroxide is highly dependent on the temperature (Fig. 4). The enthalpy of activation at $0-12^{\circ} \mathrm{C}$ (at both $\mathrm{pH} 8.5$ and $\mathrm{pH} 7$ ) is the same as for the decay of the

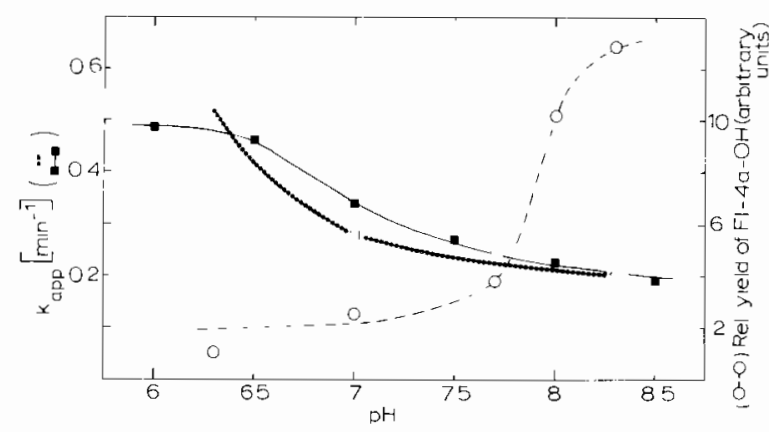

Fig. 3. pH-Dependence of stability of the luciferase-bound flavin intermediate at $12^{\circ} \mathrm{C}$. preparations of the intermediate were carried out on the aldehyde-equilibrated Sephadex G-25 column at the different $\mathrm{pH}$ values shown as described in the experimental section. The spent reaction mixtures containing the intermediate were collected in the eluates, curve $\mathrm{O}-\mathrm{O}$ shows the yield as estimated from its fluorescence emission intensity $\left(\lambda_{\mathrm{ex}}=380 \mathrm{~nm}, \lambda_{\mathrm{em}}=480 \mathrm{~nm}\right)$ measured immediately after elution. Curve a-a shows the decay rates in $100 \mathrm{mM}$ phosphate buffer, and curve $\square-\square$ the decay rates in $10 \mathrm{mM}$ phosphate buffer $+400 \mathrm{mM} \mathrm{NaCl}$ measured by following the decay of the fluorescence emission at $480 \mathrm{~nm}\left(\lambda_{\mathrm{ex}}=380 \mathrm{~nm}\right)$. 


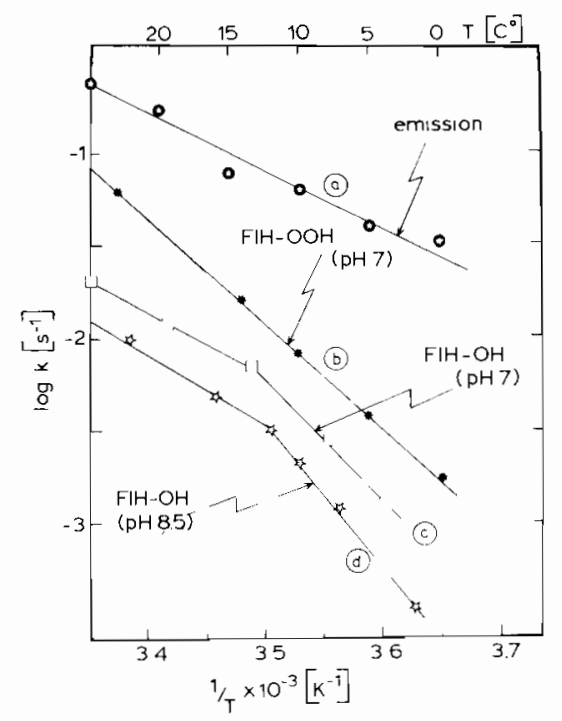

Fig. 4. Arrhenius plots showing the temperature dependence of the decay of the luciferase bound flavin-4a-hydroxide intermediate at pH 7 (c) and 8.5 (d). The temperature dependencies for the decay of the flavin-4a-hydroperoxide (b; from Ref. 17) and the bioluminescence (a) are also shown for comparison. The decay of the flavin-4a-hydroxide in $0.35 \mathrm{M}$ phosphate buffer at $\mathrm{pH} 7(\square)$ and 8.5$)(\star)$ in the presence of $0.01 \%(\mathrm{v} / \mathrm{v})$ decanal was determined at different temperatures by decrease of fluorescence emission at $480 \mathrm{~nm}$. Unlike the Arrhenius plots of the overall reaction and the decay of the flavin-4a-hydroperoxide the luciferase bound flavin-4a-hydroxide appears to have a break at about $12^{\circ} \mathrm{C}$ in its activation enthalpy. The activation enthalpies are about $60 \mathrm{~kJ} / \mathrm{mol}$ for (a), about $114 \mathrm{~kJ} / \mathrm{mol}$ for (b), and about $50 \mathrm{~kJ} / \mathrm{mol}$ at $T>12^{\circ} \mathrm{C}$ and about 118 $\mathrm{kJ} / \mathrm{mol}$ at $T<12^{\circ} \mathrm{C}$ for (c) and (d), respectively.

flavin-4a-hydroperoxide [17]. This is consistent with the assumption that the basic mechanism of stabilization of the 4a-substituent is the same for the flavin-4a-hydroxide and the 4a-hydroperoxide. As discussed earlier, this might involve a strong hydrogen bridge towards $N(5)[16]$. The enthalpies of activation are higher, however, than for the bioluminescence reaction. While the enthalpies of activation for the decay of the flavin-4a-hydroperoxide and flavin-4a-hydroxide are about the same, there appear to be differences in their entropies of activation, and also between $\mathrm{pH} 7$ and 8.5 , which may be attributable to a change in protein conformation. In contrast to the flavin-4a-hydroperoxide decay, and to the bioluminescence reaction, for which single straight lines characterize the relationship in the Arrhenius plots, the temperature- dependence of the flavin-4a-hydroxide decay shows a break at about $12^{\circ} \mathrm{C}$. The reason for this is not obvious, although it would be reasonable to assume that the flavin-4a-hydroxide and flavin4a-hydroperoxide differ slightly in their interactions with luciferase.

A major factor that might contribute to the stability, and thus to the feasibility of the isolation of the luciferase bound flavin-4a-hydroxide intermediate, is the presence of decanal. The possible effect of this molecule or the stability of the flavin-4a-hydroxide is, however, very difficult to demonstrate, since such a study would require purification of the latter from decanal.

\section{Discussion}

A major point with respect to the isolated intermediates revolves around the differentiation btween a $4 \mathrm{a}-\mathrm{OOH}$ and a $4 \mathrm{a}-\mathrm{OH}$ flavin structure. The reaction of luciferase-bound flavin-4a-hydroperoxide with a long-chain aldehyde is postulated to give the flavin-4a-hydroxide plus light and long-chain acid.

\section{$\mathrm{L}-\mathrm{FMNH}-\mathrm{OOH}+\mathrm{R}-\mathrm{CHO} \rightarrow \mathrm{L}-\mathrm{FMNH}-\mathrm{OH}+\mathrm{R}-\mathrm{COOH}+\mathrm{h} \nu$}

The absorption spectra of flavin-4a-hydroxides are not sufficiently different from those of flavin4a-hydroperoxides to allow an unequivocal differentiation [13]. The 4a-hydroxide is the logical product to be expected from an oxidation reaction such as that shown, provided no structural rearrangements occur. The occurrence of a mixture of flavin-4a-hydroxide and 4a-hydroperoxide is also a possibility to be assessed.

However, the accurate measurement of total light and of the other product, decanoic acid, would be very difficult under the conditions used for the preparation of the flavin-4a-hydroxide. The lack of light production upon subsequent addition of aldehyde to the isolated intermediate is consistent with the absence of a hydroperoxide function in the intermediate, but it does not exclude it, since a lack of light emission might result from 'inactive' hydroperoxide. In view of this, the demonstration of the absence of peroxide in the flavin-4a-hydroxide preparation was considered of utmost importance. This was carried out with two 
tests, relying on two different systems. The results (see Materials and Methods for details) were similar. With the more sensitive peroxidase test [12], we are confident that we would have detected an amount of $\mathrm{H}_{2} \mathrm{O}_{2}$ (formed from decay of the flavin-4a-hydroperoxide) corresponding to $5 \%$ of the total flavin (about $10 \mathrm{nmol}$ ) present in the preparation.

The fluorescence emission spectrum of the luciferase-bound flavin intermediate that is present immediately after the emission of light matches the bioluminescent emission spectrum very closely. It is thus postulated (Scheme I) that this intermediate is formed in the bioluminescence reaction from the proposed intermediate flavin4a-peroxihemiacetal, and that it is identical with the ground state of the emitter. The chemical structure proposed for this intermediate is thus that of a flavin-4a-hydroxide. This follows from its mode of formation, from the fluorescence emission and excitation spectra, from the ultravioletvisible absorption spectra, and from the absence of formation of hydrogen peroxide from its decay.

A matter of considerable current interest is the
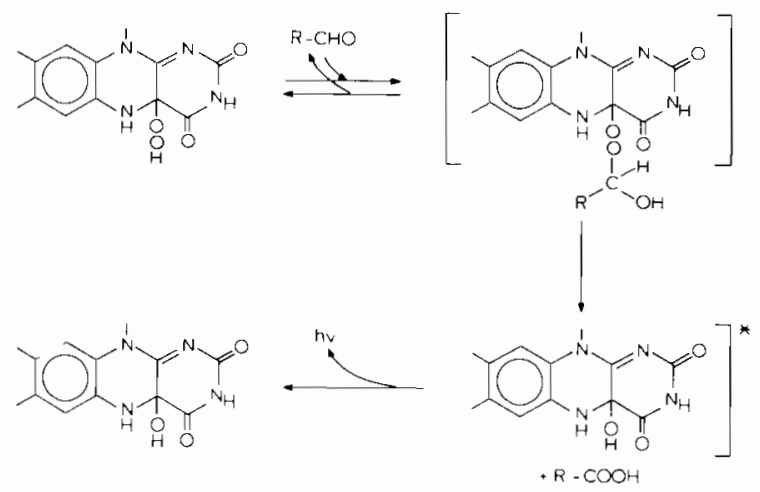

Scheme 1. Scheme proposed to represent the part of the luminescent reaction of bacterial luciferase, which involves generation of the excited emitter. Aldehyde is shown to bind reversibly to the luciferase-flavin-4a-hydroperoxide and to form a peroxyhemiacetal. This might occur via a Michaelis complex (not shown). The occurrence of the peroxyhemiacetal is postulated for chemical reasons, this species not having been detected yet. It undergoes decomposition to form the excited emitter, the luciferase-flavin-4a-hydroxide. The mechanism of this process has not yet been elucidated, and it might involve further (excited) intermediates. After light emission, or relaxation by different pathways, the flavin-4a-hydroxide eliminates water to reform oxidized FMN and free luciferase (not shown). nature of the excited chromophore that emits light $[1,18-20]$. The flavin-4a-hydroxide fulfills this role in those cases where no other light emitting chromophore is present, e.g., for purified luciferase systems such as from Vibrio harveyi. In some cases there may be a further chromophore present (bound to a secod protein) which is involved in light emission, e.g., in vibrio fischeri, strain $\mathrm{Y}-1$, with a yellow fluorescent protein [7] and in Photobacterium phosphoreum, with a blue fluorescent protein $[6,21]$. In these cases the luciferase-bound flavin-4a-hydroxide may not be the (sole) emitter, and not necessarily the primary excited state. Possible pathways leading to the generation of excited states from such different chromophores in the bacterial system have been proposed [1,19], based on the so called chemically induced electron exchange luminescence (CIEEL) mechanism [22]. In our proposal the dual role of activator and emitter may be assumed either by the flavin-4a-hydroxide itself or by a second chromophore, the latter in adventitious association with the catalytic complex. Such mechanisms are consistent with the formation of ground-state flavin-4a-hydroxide, irrespective of the excited state and/or emitter.

\section{Acknowledgements}

This work was supported in part by grants from the U.S. National Science Foundation to J.W.H. (PC 83-09414), and the Deutsche Forschungsgemeinschaft to S.G. (Gh 2-4/5), and by a fellowship to Manfred Kurfuerst (Wissenschaftsausschuss) of the North Atlantic Treaty Organization distributed by Deutsche akademischer Austauschdienst.

\section{References}

1 Hastings, J.W., Potrikus, C.I., Gupta, S., Kurfuerst, M. and Makemson, J.C. (1985) Adv. Micr. Physiol. 26, 235-291

2 Hastings, J.W., Balny, C., Le Peuch, C. and Douzou, P. (1973) Proc. Natl. Acad. Sci. USA 70, 3468-3472

3 Vervoort, J., Mueller, F., Lee, J., Van den Berg, W.A.M. and Moonen, C.T.W. (1986) Biochemistry 25, 8062-8067

4 Balny, C. and Hastings, J.W. (1975) Biochemistry 14, 4719-4723

5 Kurfuerst, M., Ghisla, S. and Hastings, J.W. (1984) Proc. Natl. Acad. Sci. USA 81, 2990-2994

6 Gast, R. and Lee, J. (1978) Proc. Natl. Acad. Sci. USA 75, 833-837 
7 Leisman, G. and Nealson. K. (1982) in Flavins and Flavoproteins (Massey, V., and Williams, C.H., eds.), pp. 383-386, W. de Gruyter, Berlin

8 Waters, C.A. and Hastings, J.W. (1977) J. Bacteriol. 131, $519-525$

9 Hastings, J.W., Baldwin, T.O. and Nicoli, M.Z. (1978) Methods Enzymol. 57, 135-152

10 Baldwin. T.O., Nicoli, M.Z., Becvar, J.E. and Hastings, J.W. (1975) J. Biol. Chem. 250, 2763-2768

11 Laemmli, U.K. (1970) Nature 227, 680-685

12 Werner, W., Riechmann, P., Rey, H., Wielinger, H., Kahle, K., Weiss, L., Klarwein, M. and Wieland, O. (1971) Quad, Sclavo. Diagn. 7, 231-242

13 Ghisla, S., Entsch, B., Massey, V. and Husain, M. (1977) Eur. J. Biochem. 76, 139-148

14 Entsch, B., Ballou, D. and Massey, V. (1976) J. Biol. Chem. $251,2550-2563$
15 Massey, V. and Ghisla, S. (1983) in Biological Oxidations, 34. Mosbach Colloquien (Sund, H. and Ullrich, V., eds.), pp. 114-139, Springer, Berlin

16 Kurfuerst, M., Ghisla, S., Presswood, R. and Hastings, J.W. (1982) Eur. J. Biochem. 123, 355-361

17 Tu, S.-C. (1979) Biochemistry 18 (26), 5940-5945

18 Ziegler, M.M. and Baldwin, T.O. (1981) Curr. Topics Bioenerg. 12, 65-113

19 Macheroux, P. and Ghisla, S. (1985) Nachr. Chem. Tech. Lab. 33, 785-790

20 Matheson, I.B.C. and Lee, J. (1983) Photochem. Photobiol. 38, 231-240

21 Koka, P. and Lee, J. (1979) Proc. Natl. Acad. Sci. USA 76, 3068-3072

22 Schuster, G.B., Dixon, B., Koo. J.-Y., Schmidt, S.P. and Smith, J.P. (1979) Photochem. Photobiol. 30, 17-26. 